\title{
Ecological Discourse Analysis and Protection Countermeasures on Zhoushan Fisherman's Song
}

\author{
Pingping Yan, Jingjing Lu, Hongying Li, Zhijie Chen \\ ${ }^{1,2,3}$ School of Froeign Languages, Zhejiang Ocean University, Zhoushan, China \\ *Corresponding Author: Pingping Yan, School of Froeign Languages, Zhejiang Ocean University, \\ Zhoushan, China
}

\begin{abstract}
Eco-linguistics is an interdisciplinary subject of ecology and linguistics. This paper aims to dig out the current situation and the corresponding countermeasures and reasonable proposals of Zhoushan fisherman's song as an endangered language in the perspective of Eco-linguistics. The analysis of register theory, including the field of discourse, the tenor of discourse and the mode of discourse of Zhoushan fisherman's song helps us to better understand man-sea relation, to provide a solid theoretical support for inheriting marine folk culture, to protect marine ecological environment, to achieve sustainable development of fishery economy and build Zhoushan into a powerful "Fisheries City".
\end{abstract}

Keywords: Eco-Linguistics, Zhoushan Fisherman's Song; Protection Countermeasures

\section{INTRODUCTION ON ECOLINGUISTICS}

For several decades, with the rapid growth of population, environmental pollution as well as the excessive exploitation and the unconscionable using of the resources, the earth's ecological environment has suffered unprecedented damage. The extinction rate of global species is accelerating, biological species and the diversity of resources is suffering heavy losses and many species are extinct and endangered. The global environmental degradation has led to people's strong desires for a harmonious environment. The scholars of different disciplines are also actively looking for various ways to prevent the further deterioration of ecological environment. Based on such a background, a new linguistic branch - Eco-linguistics appears. Ecological linguistics is an interdisciplinary subject of ecology and linguistics. It aims to reveal the interaction between language and environment by studying the ecological factors of language and the relationship between language and ecology. It has two major branches: language ecology and critical Eco-linguistics.

Einar Haugen(1971) first defined language ecology as " the study of interactions between any given language and its environment" in his book - The Ecology of Language in 1971. He also described the interaction between language and its surrounding environment was in analogy with the relationship between animals, plants and the environment and focused on the study of the environmental factors which either strengthen or weaken the language function. Thus the metaphor of language ecology began to be accepted by language researchers. The concept, principles and methods of bio-ecology were used for language study, which was further expanded by some German scholars to form the theory of ecological linguistics. In 1990, H.A.K. Halliday(1990) emphasized the relationship between a specific language and it's growth, gender and species. He advocated that linguistic researches should pay more attention to the relationship between language and environment and do not ignore the role of ecological processes. What's more, he proposed that language research should be studied as an integral part of the ecological study, in other words, Eco-linguistics should view language and the study of language as an integral part of ecological issues to analyze the role of language in ecology. As an interdisciplinary subject, Eco-linguistics considers language as an inseparable part of the ecosystem and believes that the language system is influenced by its ecological environment. There is a direct relationship between the generation and development of language and the natural factors and social factors of the ecosystem, which has provided a new approach to linguistic research.

\footnotetext{
${ }^{1}$ This is one of the achievements about The Project KT2015037 from Zhejiang Higher Education Institute: An Empirical Study of the return of the Texts to the Originals in Chinese College English Class from the Perspective of New Narratology
} 
Therefore, ever since its establishment in the early1970s, Eco-linguistics has expanded into a wide range of theoretical and applied fields concerning the interrelationship between language and its environment. Hence, a completely different research paradigm is established between language and ecology, providing solid theoretical support for us to prevent deterioration of environment and protect our ecological environment.

\section{INTRODUCTION ON ZHOUSHAN FISHERMAN' S SONG}

The natural condition of Zhoushan, Zhejiang is advantaged and the abundant fishery resources make Zhoushan Fishing Ground one of the world's four largest fisheries. The people of Zhoushan have been fishing for generations. What's more, everything on the boat is done by hand, so collective labor is extremely burdensome. In order to cooperate with a series of heavy manual labor on board, people in every process call for a unified action and mood adjustment. Zhoushan fisherman's song was born in such a case. It's a cultural outcome that the island fishermen create spontaneously in the long-term productive labor practice.

Zhoushan fishermen are the main singers of the Zhoushan fisherman's song. According to the hard part of the operation, Zhoushan fisherman's song is divided into more than twenty categories such as hand-drawing song, hand -shaking song, hand-pulling song. (手拔类号子、手摇类号子、 手扳类号子)And according to the operation procedures, fisherman's song is divided into pulling-tent song, weighing-anchor song, pulling-net song, etc. (拔篷号子、起针号子、拔网号子) According to the amount of effort involved in the operation, it can be divided into big-size song and small-size song（小号和大号）. All kinds of songs are flexible and versatile at the same time.

It has a unique style and a strong sense of marine life. There are many characteristics such as short and colloquial, diverse varieties, strong dialects, impromptu freedom, bold style, strong sea flavor and so on. These can be expressions of the fisherman's optimistic, heroic, simple, and unrestrained personalities. The fisherman's song is derived from marine fishery labor and marine fishery work. Thus it demonstrates the relationship between command and subordination as a means of unifying paces as well as their wills. It is the product of traditional marine fishery and it is the cultural carrier of original manual production. As an ancient and unique folk art form and as evidence of the history of traditional fishing in Zhoushan, it embodies the distinctive features of Zhoushan's marine culture, and it has profound historical value and unique artistic value. It provides people with the platform to learn and get familiar with Zhoushan fishermen.

Fisherman's song is not only restricted by labor intensity, but also by the level of production technology. With the gradual modernization and high technology of marine fishery labor mode, some of the heavy physical labor that many fishermen need to join is gradually diminishing. Under the background of traditional fishing industry and shipping, fisherman's song has developed and thrived, but today the living space of fisherman's song is shrinking. A lot of centuries-old traditional fisherman's songs are on the verge of disappearing.

\section{Analysis on the ECOlOgical CONTEXT OF ZHOUShan Fisherman's SONG}

\subsection{The Deterioration of Ecological Context of Zhoushan Fisherman's Song}

Science and technology is a double-edged sword. It also has some negative effects when it brings human beings a lot of convenience. With the development of technology, human beings have developed more sophisticated and advanced tools, acquiring the ability to break through some certain restrictions of natural environment and lessen their labor intensity greatly. However, the damage caused by it becomes much more severe.

On the one hand, the advanced fishing tools led to less use of Zhoushan fisherman's song. In the age of science and technology, outdated technology has been replaced by advanced technology and the way of traditional manual fishing has been replaced by that of modern mechanical fishing. From the late 1960s, motor sailboats gradually replaced the wooden boats. Then in the late 1980s, the use of steel fishing vessels led to the elimination of motor boats. At the same time, fishing tools were also improved, those commonly used ones, such as sails, paddles and oars were abandoned. Mechanization replaced the heavy manual labor. The fisherman's song, which was originally designed to cooperate with fisherman's sea operations, disappeared in the later practices.

On the other hand, the aggravating pollution of marine environment and overfishing in marine fisheries have destroyed the ecological balance system of the ocean, resulting in the decrease of 
fishery resources. Many kinds of fishes are disappearing from our view. As a consequence, the disappearance of the fish has reduced the fisherman's work as well as the use of fisherman's song. Only when it comes to protecting the marine environment can we realize the urgent need to protect fishery resources and strictly observe the bans.

In current ecological contexts, the living environment of the fisherman's song was squeezed out of the place by modern civilization, making it an endangered local language.

\subsection{The Decline of Numbers of Inheritors of Zhoushan Fisherman's Song}

"Hagen mode" believes that language has its own ecological environment, and the attitude of speakers determines the living environment of language . (Hagen, 1970) Hence, speakers play a very important role in protecting and inheriting the intangible cultural heritage-Zhoushan fisherman's Song. Inheritors shoulder more social responsibilities than common people. In the real society, fishermen gradually realize that the trend of mechanization is irresistible. There is no doubt that they should keep up with the fast-paced life of modern society and get familiar with high-techs, otherwise, only with their own strength and the fisherman's song, they will easily fall behind others and the time. Therefore, the use of fisherman's song decreased and fisherman gradually forget it. Besides, artists who are masters of the fisherman's song are getting older and older and the inheritors of Zhoushan fisherman's song have become increasingly rare. Physical limitations prevent them from propaganda and teaching of fisherman's song, so the inheritance of fisherman's song is drastically reduced. This is also the reason why the public awareness of protection is still lacking.

\section{Ecological Discourse Analysis of Zhoushan Fisherman's Song}

According to M.A.K Halliday (1976), "Language varies as its function varies; it differs in different situations." The type of language which is selected as appropriate to the type of situation is a register. Halliday (1985) further distinguishes three social variables that determine the register: field of discourse, tenor of discourse, and mode of discourse. The three variables are the features of the context of situation which determine the features of language appropriate to the situation, i.e. register. And they determine the register collectively, not piecemeal. Zhoushan fisherman's song can be interpreted by Halliday's register theory. It has some changes in different periods and situations along with different functions.

As for the first register, the field of discourse is concerned with fishing on the sea during the period of agricultural civilization. Fishermen used more primitive tools such as sailing boats, sculls, etc. What else the fishermen could make use of was their force of body and extremely tough perseverance in order to fight against the force of sea and to obtain the valuable treasures of the sea. However, these elements were far from enough to achieve that goal. The force of nature was a key element as well, and undoubtedly it was closely related to the sea. The ocean was unknown, mysterious and full of risks and challenges to mankind. Human beings were insignificant in comparison to the ocean, they had little strength, and with only these commonly used tools, they could not compete with the forces of nature. Hence, the fish productivity was greatly relied on the ocean. In other words, fishes were just considered by people at that time as gifts from the ocean. Fishing on the sea was really a dangerous thing for them. This was also the reason why there were always sacrifices to the sea before fishermen went to sea for the reason of a smooth sailing and a big catch of fish. Due to this reason, the tenor of discourse showed the relationship between those fishermen and nature. The power of nature was so enormous that almost all the fishermen reverenced the nature very much. The fishermen attached great importance to the ocean in their lives. There was no doubt that they could by no means do harm to the ocean. On the contrary, they did everything available to show their respect to the ocean and expect the rewards from it. In this way, the man-sea relationship was harmonious and united. Besides, the precentor sang the lead and the rest joined in the chorus. The mode of discourse was oral. Zhoushan Fisherman's song had different varieties and was a typical representative of Zhoushan dialect consisting of its distinctive regional and cultural features.

(1) “真要呀, 求老天公, 吔啰烸, 好风呀, 还要送呀, 吔啰烸。”(《摇橹号子)

(2) “求求龙王发善心, 救救苦命小儿郎。” (《抲鱼人祈祷龙王》)

(3)

“浪岗三块团呀, 玉秃老蟹鳗呀。抲来种小因呀, 蟹要蟹排球呀。蟹排龙灯球呀, 蟹排来结球

呀。结球把我船装满呀。”(《拔网号子》) 
(4)天上有多少星星，烸哟！地上有多少人丁，烸哟！海上有多少珍珠宝贝，烸哟！诸葛亮， 烸哟！刘伯温, 嗨哟! 数拉格数不清吓, 烸哟！”(《起网号子》)

$$
\text { 5)一拉金嗨哟，二拉银烸哟，三拉珠宝亮晶晶，大海不负抲鱼人呵。”(《起网号子》) }
$$

(6)

“嗨嘞个哈嘞个烸嘞个哈！嗨哈嘞个烸嘞个哈！正月会开牡丹花, 二月会开水仙花, 三月杜鹃 是清明,

四月菩薇伴篱笆, 五月石榴红似火, 六月荷花映水下, 七月稻花遍地开, 八月桂子嫦娥家, 九 月菊花小蒸头, 十月阳春芙蓉花, 十一月草子小浪花, 十二月腊梅白花花。抲鱼人有福勿会享 , 一年四季看浪花。”(《摇橹号子》)

From these words we can realize that Zhoushan fisherman' s song vividly depicted the inexhaustible marine resources, and reflected a series of unknown dangers to the fishermen at sea and showed the fisherman's strong will and courage in obtaining those fishery resources, playing a very important role in cheering the fishermen up in such tiring work and demonstrating the harmonious and united mansea relationship.

Concerning the second register, it processed in the late 1970s just right after the proposition and implement of the policy of reform and opening-up, the field of discourse was also concerned with fishing on the sea. However, there was one thing that had changed, that is, thanks to the manufacture of motor sailboats, fishermen used motor sailboats instead of these primitive tools. On the one hand, the risk of fishing on the sea was enormously reduced. On the other hand, the rapidly development of manufacture of motor sailboats resulted in increasing number of fishing boats, excessive fishing intensity and even overfishing. As a result, the fishery resources declined continuously. The deteriorating marine environment was an unavoidable natural result of the above-mentioned changes. It had a lot of signs for human beings to notice. For instance, the oil was given away by fish boats and floated on the surface of the ocean, causing great damage to the marine environment and the numerous deaths of marine creatures. Another example was that the noise produced by machines in the process of fishing operations led to the loss of the creatures' ability to move and their deaths or their migrations to other sea areas. Such causes and examples were countless. However, it might be concluded as that while human was benefiting immensely from the ocean without considering the consequences, marine ecological environment was causing unprecedented destruction as well. At the same time, the tenor of discourse changed accordingly. The fisherman's awe to the nature decreased in spite of the fact that they still seemed insignificant in the face of nature because they believed that human beings would have the ability to conquer nature one day and there was no need worrying themselves and awing nature too much, let alone that they had already made great progress in making more advanced tools by using high-techs. It was a typical representative of Anthropocentrism. It was quite obvious that the wrong environmental morality of human centralism did no good to the environment at all and it would make the contradiction between man and environment become more and more acute and striking. Hence, the mode of discourse could be reflected in the less use of Zhoushan fisherman's song. To a certain degree, Zhoushan fisherman's song lost some of its pragmatic values and became less focused than the previous period.

With regard to the third register, the field of discourse concerns steel fishing vessels rather than motor sailboats. These steel fishing vessels process complete equipment and advanced technology, which surely decrease the fisherman's physical labor and are able to defend various kinds of marine risks, not to mention almost every fishing boat is equipped with GPS navigation system. As long as danger arises, rescue efforts will be set out relying on the information they have received from the system. With such advanced equipment, the risk on the sea is greatly reduced, and men tend to invade and conquer the sea. The environment of the ocean has been deteriorating consistently primarily because of people's ignorance and neglect of the significance of it. Human beings tent to take a lot of things for granted, and the environment of the sea is exactly one of them. In terms of the tenor of discourse, human beings are above the sea, with the attitude of mastering the ocean according to their own will. The ocean is not supreme any more. Now People totally believed that human beings have already acquired the ability to conquer nature. They do not come to realize that both people and everything natural actually belong to the same life community and the changes of man-nature relationship not only harm nature and society, but also will in turn hurt human beings themselves. What they are concerned about is merely profit. People usually run for short-term benefit, but turn a blind eye to the 
future development. It is not rational to grab short-term revenues at any long-term cost. Hence, we should by no means be mislead by the interests of immediate. The mode of discourse could be illustrated by the little use of Zhoushan fisherman's song. Its artistic conception and meaning fade away along with the changes of time. Zhoushan fisherman's song nearly lose all of its substantive value and it just becomes people's recall and pursuit of the beauty of nature and the beauty of purity of that specific time.

The change of the register reflects the changes of situation and function in different times. In different period, the connotation and value of Zhoushan fisherman's song is influenced by people's mentality and behaviour and has changed a great deal. The process is characterized by the development of Anthropocentrism. It can also be called human-centrism, which means that human beings are in the center of the whole world other than anything else, and that human beings can do whatever they want to please and benefit themselves. It is no doubt that such a thought harms the nature, human beings as well as the the whole world. In order to construct the scientific view of ecological ethic, we must turn Anthropocentrism into Eco-centrism. It calls on man's profound understanding of nature and of himself, and more importantly, the relationship between nature and human beings. Only in this way, can they reflect what they have done to the nature, reorient their relation with nature, coexist with nature and have a confidence on the path of sustainable development. Kahlil Gibran (1995) once said that "You and the world you live in are but a grain of sand upon the infinite shore of an infinite sea." Ocean plays a powerful role in many aspects, we cannot take it for granted. Otherwise, the nature we harms will take revenge and we human beings will be severely punished by it. Thus, we must take it seriously and keep a harmonious relationship with it. The long-term sustainable development is our final goal, but not the instant interests.

\section{The Protection ANd Inheritance of Zhoushan Fisherman's Song}

In Zhoushan, the fisherman's song is just like a cultural card as well as the crystal and gem of the labor and wisdom of the Zhoushan fishermen of the past generation. It is an irreplaceable part of our folk culture and marine cultural. If we do not protect and inherit it, a few years later, our descendants will have no chance of appreciating this unique folk art, nor will they be able to understand the spirit and wisdom of the fishermen of Zhoushan. Protecting the fisherman's song is to protect our spiritual homeland. Obviously, this is also something that the government should do to promote traditional culture and build spiritual civilization. In order to enable people to protect and inherit Zhoushan fisherman's song, we put forward the following suggestions.

\subsection{Carry Out Publicity and Propaganda}

Playing Zhoushan fisherman's song on television, radio, Internet and other media help increase the audience's awareness; shoot videos of Zhoushan fisherman's song and delivery them as a gift; encourage excellent art programs of Zhoushan fisherman's song to participate in various kinds of art competitions or performances.

\subsection{Provide Display Platform}

Cultural departments and relevant agencies, enterprises and institutions should provide more opportunities to perform Zhoushan fisherman's song on some traditional festivals such as Xu Fudong Dongdu Festival, China Ocean Culture Festival and China Island Tourism Conference. At the same time, inheritors of fisherman's song can be invited as "lecturer" into schools, government agencies and enterprises, telling the story of fishermen and promoting marine culture. For example, Haishan Primary School in Dinghai District invites the Hong Guozhuang, an old artists who enjoy the title "master of fisherman's song" as their teacher.

\subsection{Build a Team of Inheritors}

The essence of the intangible cultural heritage is closely linked with the inheritor, which make the selection and protection of inheritors the key of protection work. In Japan and South Korea,the government offers financial subsidies to the heirs and provide them with special treatment, such as free medical treatment, and a fairly high social status. Zhoushan should learn from other countries' experience of formulating the protection method of the inheritor. What's more, inviting old artistes of fisherman's song to tutor those new apprentices and give them monthly payment of subsidies as well as special medical treatment. Tutoring apprentices and passing on their skills enable them to fulfill their wish to protect their heritage. 


\subsection{Strengthen Training and Tutoring}

In recent years, some primary and secondary schools in Zhoushan opened the second class of musiclearning to sing the Zhoushan fisherman's song. After years of singing by teachers and students in various occasions, fishermen' s song has achieved a certain degree of popularity and obtained a group of successors. City Cultural Center can take advantage of the carrier of Enterprise culture, sending cadres to these institutions to arrange some fisherman's song performance. Diversified forms of "fishermen' s song gonging into the classroom" activities can be held in colleges and universities, allowing more students to understand the fisherman's song and we can pick the successors of the fisherman's song among them.

\subsection{Increase Capital Investment}

In recent years, during the process of the inheritance and protection of fishermen' s song, the rate has been slowed down due to lack of funds. So relevant departments should increase capital investment, or arrange public fund-raising and set up a special Zhoushan intangible cultural heritage protection fund to provide adequate funding for the construction of large-scale intangible cultural exhibition hall, ordinary people's cultural hall and Intangible Cultural Heritage Festival.

\subsection{Intensify Policy Support}

Relevant government departments need to promulgate relevant legal documents to put the protection of Zhoushan fishermen' s song formally on the agenda. At the same time, government should use media resources to increase publicity and arrange civilian staff to visit the countryside on a regular basis.

\subsection{Promote University-Industry Collaboration}

Governments, universities and enterprises should enhance communication and cooperation by conducting regular seminars and exchanging the latest research results. University team research and active cooperation with the enterprise should be encouraged to achieve a sustainable development while protecting and utilizing cultural heritage resources.

\section{CONCLusions}

On the background of the rapid development of technology and the society, the mentality of human beings has changed, the ocean's ecological environment has suffered unprecedented damage and the man-sea relationship has become worse. Based on that, an interdisciplinary subject of ecology and linguistics-Ecological linguistics comes into being. Its aims to reveal the interaction between language and environment. As an endangered language, Zhoushan fisherman's song is gradually losing its pragmatic value in nowadays' society, resulting from the change of environment and the thought of people, the decline of inheritors of Zhoushan Fisherman's Song and some other realistic reasons. However, we must try our best to protect and inherit it due to the reason that it plays an important role in many significant aspects. It is urgent to turn Anthropocentrism into Ecologycentrism. By ecological discourse analysis of Zhoushan fisherman's song, we dig deep into the current situation of it and put forward the corresponding countermeasures and reasonable proposals of Zhoushan fisherman's song in the perspective of Eco-linguistics. In this sense, we can better understand man-sea relation, coexist with the ocean, protect marine ecological environment, inherit marine folk culture, achieve sustainable development of fishery economy and build Zhoushan into a powerful "Fisheries City".

\section{ACKNOWLEDGEMENTS}

This paper has been finished within three months. The process is full of challenges and obstacles, but it is inspiring and rewarding. Thanks to the support and help of my fellow students and my teachers, I have overcome all the difficulties, such as the limit of time, the sophistication of the topic and my abilities in using English language and so on. My fellow students provide me with a large amount of useful information which is closely related to the subject and help me solve several trivial matters, greatly saving the valuable time and energy for me. I would also like to thank all of my teachers, for without their earnest teachings, I wouldn't have the knowledge, the motivation and the confidence to finish such a demanding paper. My special thanks goes to my thesis adviser, Ms. Lu jingjing. She offers careful guidance in choosing the topic, organizing the framework and even adjusting the details of the paper. The opinions put forward by her precisely broaden my horizon and give me some hints about what to do in the next step. Honestly speaking, the finish of my paper is partially due to her guidance and help. And also, I am grateful to all the experts and scholars for their excellent ideas and 
masterpieces, which become the basis of my paper. Once again, I would like to express my heart- felt gratitude to all the above mentioned people. Meanwhile, as an old saying goes, gold can't be pure and man can't be perfect, I am quite sure that there are inadequacies or even mistakes in my paper because of my academic level, and I accept and appreciate the criticism and correction of good-will from experts.

\section{REFERENCES}

[1] Einar Haugen.(2012). The Ecology of Language. Shanghai: Shanghai Foreign Language Education Press

[2] H.A.K.Halliday.(1990). The Language Of Science. Beijing: Beijing University Press

[3] Einar Haugen.(2012). The Ecology of Language. Shanghai: Shanghai Foreign Language Education Press

[4] Weidong Dai. (1988). A New Concise Course in Linguistics for Students of English. Beijing: Beijing University Press

[5] H.A.K.Halliday. (1976). Cohesion in English. London: Longman

[6] H.A.K.Halliday.(2004). An Introduction to Functional Grammar. the United States of America: Oxford University Press

[7] Gibran Kahlil(2015).Sand and Foam. Beijing: Foreign Language Teaching and Reseach Press

\section{AUTHORS BIOGRAPHY}

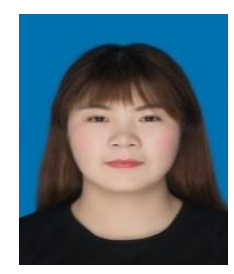

Pingping Yan, China, was born in Zhejiang, China on Oct,11, 1996. She is currently a college student in Zhejiang Ocean University, Zhoushan, China. Her research interests include ecology and linguistics.

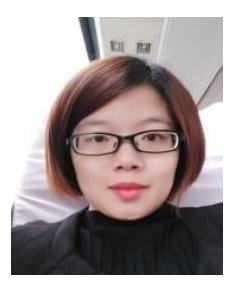

JINGJING LU is an associate professor in Foreign Language College, Zhejiang Ocean University, Zhoushan, China. She received her M.A. degree in linguistics and applied linguistics from Huazhong University of Science and Technology, China in 2006. Her research interests include cross-culture communication, English teaching and discourse analysis.

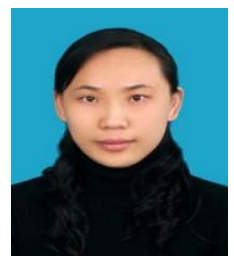

HONGYING LI is an associate professor in School of Foreign Language in Zhejiang Ocean University, Zhoushan, China. She graduated from Huazhong Normal University in 2003 and got her M.A. degree. Her research interests include discourse analysis and English education.

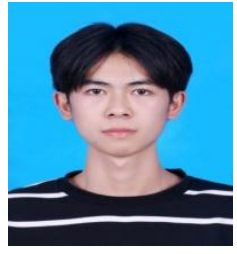

Zhijie Chen, was born in Zhejiang, China on Aug, 8, 1997. He is a college student in Zhejiang Ocean University, Zhoushan, China. His research interests include linguistics and ecology.

Citation: Pingping Yan et.al. "Ecological Discourse Analysis and Protection Countermeasures on Zhoushan Fisherman's Song". International Journal of Humanities Social Sciences and Education (IJHSSE), vol 5, no. 4, 2018, pp. 116-122 doi: http://dx.doi.org/10.20431/2349-0381.0504014.

Copyright: (C) 2018 Authors. This is an open-access article distributed under the terms of the Creative Commons Attribution License, which permits unrestricted use, distribution, and reproduction in any medium, provided the original author and source are credited. 